Article

\title{
Estimating Age-Specific Natural Mortality for Sandfish in the Eastern Coastal Waters of Korea
}

\author{
Giphil Cho ${ }^{1}$, Daewook Kim ${ }^{2}{ }^{\circledR}$, Sukgeun Jung ${ }^{3}$, Il Hyo Jung ${ }^{4}$ and Sangil Kim ${ }^{4, *}$ \\ 1 Finance-Fishery·Manufacture Industrial Mathematics Center on Big Data, Pusan National University, \\ Busan 46241, Korea; giphil@pusan.ac.kr \\ 2 Department of Mathematics Education, Seowon University, Cheongju, Chungbuk 28674, Korea; \\ kdw@seowon.ac.kr \\ 3 Department of Marine Life Science, Jeju National University, Jeju 63243, Korea; sukgeun.jung@gmail.com \\ 4 Department of Mathematics, Pusan National University, Busan 46241, Korea; ilhjung@pusan.ac.kr \\ * Correspondence: sangil.kim@pusan.ac.kr; Tel.: +82-51-510-2209
}

Received: 25 August 2020; Accepted: 16 September 2020; Published: 18 September 2020

\begin{abstract}
To estimate age-specific natural mortality, we proposed an age-structured biomass model with an impulsive dynamical system. In the estimation of natural mortality, we considered growth rate and also reproduction rate, growth, and catch of sandfish, Arctoscopus japonicus. Assuming a linear relationship between observed values of the catch per unit effort (CPUE) and total biomass estimated by the age-structured biomass model, we estimated the age-specific natural mortality using the CPUE and catch data, from 1994 to 2009, for varying values of the assumed initial total biomass in 1994 , by selecting the largest coefficient of determination $\left(R^{2}\right)$. We suggested the following empirical formula: $M_{i}=\frac{q}{K L_{\infty}} \ln \left(\frac{e^{K\left(i+1-t_{0}\right)}-1}{e^{K\left(i-t_{0}\right)}-1}\right)$, which estimated natural mortality of sandfish, and the derived age-specific natural mortality was significantly related to fecundity and growth. The parameters of von Bertalanffy growth equation and a logistic equation of maturity with total length were derived from the data of otolith and gonad analysis of female sandfish collected from 2005 to 2008 and from 2005 to 2006, respectively. We also conducted sensitivity analysis by varying the exponent in the inverse function of total length.
\end{abstract}

Keywords: natural and fishing mortality; parameter estimation; age-structured model; sandfish; impulsive differential system

\section{Introduction}

The sandfish, Arctoscopus japonicas (Steindachner), is a species belonging to the family Trichodontidae (order Perciformes). The sandfish is mainly caught in the east coastal area of Korea and Akita Prefecture of Japan [1-4]. The ecology of sandfish was studied by Mio [4] and their life history in the eastern coastal waters of Korea was reviewed by Lee et al. [3]. The hatched larvae and juveniles from the spawning region inhabit at the depth of $10 \mathrm{~m}$, while adults reside at the depths of 200-300 $\mathrm{m}[2,5-7]$. The main habitats of adults are the eastern coastal waters of Korea and the northern and western coastal waters of Japan [8-10]. Sandfish are scattered in the thick seaweed at 2-10 m depths of the eastern coastal waters of Korea from Samcheok to Sokcho [2] during the spawning season in November-December [1,4]. Sandfish have been traditionally important commercial fish species in Korea [2,11]. However, since 1970, catch has continued to decrease from 25,000 metric tons in 1971 to 3900 tons in 2009. For developing fisheries, the management of sandfish in the eastern coastal waters of Korea, as well as reliable estimates of natural and fishing mortality of sandfish are critical for stock assessment. However, only Watanabe et al. [12] and Lee et al. [11] estimated the natural mortality of sandfish using Pauly method [13] and Zhang and Megrey method [14], respectively. 
An accurate estimate of natural mortality is critical for fishery stock assessment and management. It has been difficult to estimate, because natural deaths are rarely observed [15]. However, it is appropriate to assume the natural mortality for adult stage of the model to be a constant value for the stock assessment. However, as bigger fish have fewer predators than smaller ones and natural mortality of larvae and juveniles is known to decrease with increasing body size [16-18], a size-dependent mortality model for stock assessments could make it more realistic, in particular, when small fish are also concerned $[19,20]$. Length-inverse mortality models have been proposed independently by several authors (e.g., [21]), and are supported by empirical analyses [20,22]. Of particular relevance to the present study is Lorenzen's analysis [22] on release experiments, which demonstrated that the length-inverse mortality pattern can be valid for a wide range of marine fish species.

However, Lorenzen's analysis has limitations for obtaining natural mortality of a specific fish species. In addition, most methods of estimating size-dependent natural mortality do not take into account the reproduction capacity which can determine the life-time natural mortality. Thus, Jung et al. [16] proposed a matrix projection method to estimate and validate size-dependent instantaneous rates of natural mortality for fish, based on their fecundity and growth. Their main assumption was that size-dependent natural mortality could be calculated numerically based on a steady-state hypothesis. However, their natural mortality was estimated in the absence of fishing. Therefore, their approach is valid only when it is presented using a method for estimating natural mortality under the assumption of long-term equilibrium in the absence of fishing, and cannot be extended to estimate natural mortality in real fishing conditions.

An underlying mechanism of density-dependent mortality of fish is intra-species competition for food, habitat, or other resources $[23,24]$. Various studies have considered density-dependent mortality for estimating the biomass of fish [25-28]. Here, we have tried to estimate density-dependent mortality that could estimate the most appropriate natural mortality.

Fisheries scientists have described growth and mortality of fish through discrete age-structured models (e.g., Leslie matrix) that could easily express age-specific growth and mortality. Discrete models assume a constant value of catch for a fixed period. Some discrete models assume that all catches occur at the same time in one year [29-32]. We would like to consider a fish model that applies consistent constant catch in the time interval. Continuous models can solve this problem, but need more complex equations, such as a delay differential equation or a partial differential equation, to represent age structure. However, an impulsive model composed of an ordinary differential equation can solve this problem and take advantage of both discrete and continuous models. Recently, impulsive differential equations have been used to represent an age-structured model [33].

The purpose of this paper is to propose a method of estimating age-specific natural mortality with an age-structured biomass model and estimate the age-specific natural and fishing mortality of sandfish for various initial total biomass, in 1994, in the eastern coastal waters of Korea. The equations used are ordinary differential with an impulsive term, which seems convenient. In particular, the von Bertalanffy growth model is quasi-linear at the start and saturates in an asymptotic way realistically. We derive their age-structured biomass model from the age-structured population model and simulate numerically the impulsive dynamical system to estimate the natural and fishing mortality rate of sandfish based on catch per unit effort (CPUE).

It should be noted that discrete models can only calculate individual time moments and cannot produce results between time interval. In addition, for variables (growth rate, etc) that can change sensitively over time, the same values should be used within a time interval. For example, if one sets up a discrete model of time interval, then the same annual growth rate cannot be applied, and one cannot estimate the results even if one wants to analyze the results of monthly units (resource, catch mortality, etc.), which are smaller than annual units which are in this paper. This problem can be solved by using a continuous model such as ordinary differential equations, but these equations are difficult to express the movement of the stages. Therefore, in this study, we have proposed an ordinary different equation 
with an impulse to complement both of these problems. As a solution to this problem, various ordinary different equations with an impulse have been studied [34-38].

The remainder of this article is organized as follows: In Section 2, we describe study data and methodologies of estimating natural mortality of the sandfish based on the age-structured model; om Section 3, we present simulation results including estimation and sensitivity of natural mortality and estimation of parameters in the model; and in Section 4, we provide an extensive discussion and conclusions.

\section{Materials and Methods}

In order to utilize the relationship between CPUE and total biomass of sandfish in estimating natural mortality, an age-structured mathematical model of sandfish is considered. By estimating the growth and reproduction parameters in the mathematical model using total length and maturation data based on annulus counting of otoliths, we can represent the total biomass of sandfish according to natural mortality. Thus, we estimate the natural mortality of sandfish by using linear regression taking the greatest value of the coefficient of determination $\left(R^{\wedge} 2\right)$ for the relationship between CPUE and total biomass of sandfish. A flow chart describing the procedures to estimate natural and fishing mortality of sandfish in the eastern coastal waters of Korea is provided in Figure 1.

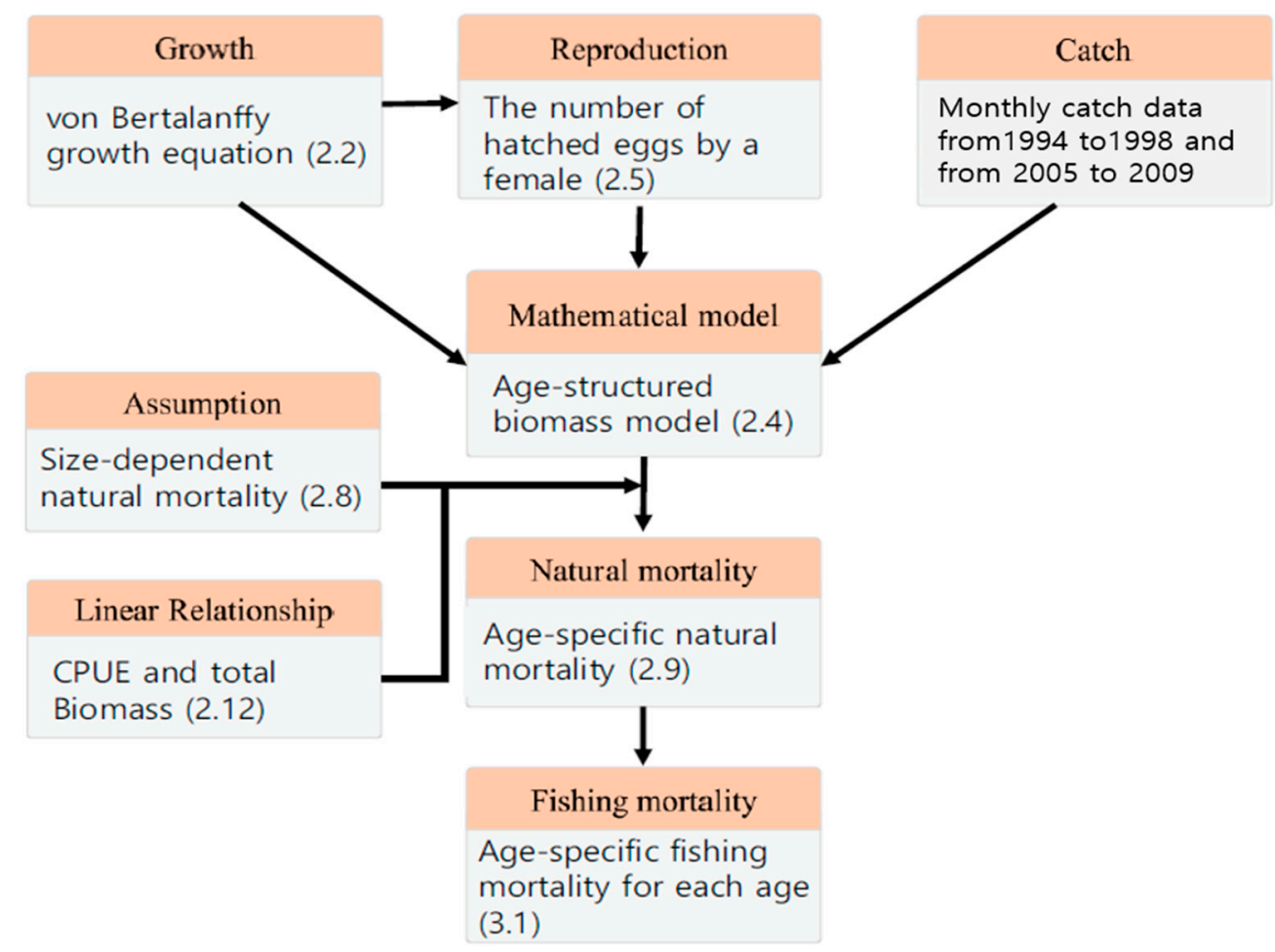

Figure 1. Schematic flowchart summarizing the methods used to estimate natural morality of sandfish in the eastern coastal waters of Korea. The number in parentheses indicates the equation number related to the description in the paper.

Three types of data were collected, including total length data for age from 2005 to 2008 which was based on annulus counting of otoliths from 46 female sandfish, sexual maturity with total length of 126 female sandfish collected during spawning season (December 2005 and December 2006), and CPUE and catch data for sandfish from 1994 to 2009. All types of data were obtained from the National Fisheries Research and Development Institute. The total length and sexual maturity data were used to estimate the von Bertalanffy growth equation and probability of participation for spawning of sandfish using regression analysis. The CPUE and catch data were used to estimate the natural mortality of sandfish for each age according to a linear relationship. 


\subsection{Age-Structured Population Model}

Here, we consider an age-structured population model of sandfish by applying the impulsive system which has been described in various articles and textbooks of mathematical biology and mathematics $[33,39,40]$. The sandfish population can be divided into 6 age classes (the juvenile stage before recruit and the adult stage after recruit from 1 to $5 \mathrm{yr}$ ):

$N_{0}$ The number of individuals of juvenile;

$N_{i}$ The number of individuals of adult at age $i, 1 \leq i \leq 4$;

$N_{5}$ The number of individuals of adult over the age of 5 .

Generally, the number of each age class is governed by the three biological processes in their life cycle, i.e., spawning and the shift to the next age class through growth and aging. The sandfish spawn only once from November to December in each year (total spawner). Death rate is expressed as instantaneous rates of natural and fishing mortality. Because it is difficult to express age movements using ordinary differential equations, these are represented by impulse on the first day of each year. For convenience, we take the following assumptions:

1. Sandfish spawn only in December;

2. Sandfish hatch all eggs on January 1;

3. All ages classes of sandfish transfer to the next age class on January 1 if they survived.

Thus, the age-structured population model of sandfish can be expressed as follows:

$$
\left\{\begin{array}{c}
\frac{d N_{i}(t)}{d t}=-\left[M_{i}+D N_{i}(t)\right] N_{i}(t)-H_{i}(t) t \neq n \\
N_{0}\left(t^{+}\right)=\sum_{i=0}^{5} f_{i} N_{i}(t) \\
N_{j+1}\left(t^{+}\right)=N_{j}(t) \\
N_{5}\left(t^{+}\right)=N_{4}(t)+N_{5}(t)
\end{array}\right\} t=n
$$

where $i=1, \ldots, 5, j=0,1, \ldots, 3, n \geq 1(n \in \mathbb{N})$, and $t^{+}$represents the right limit of time. Natural mortality and number of fishing at age $i$ is given by $M_{i}$ and $H_{i}$, respectively; $f_{i}$ is the effective fecundity, which is explained in the next section; and $D$ is a density-dependent mortality coefficient.

The density-dependence mortality of juveniles is widely documented and is assumed to be an important mechanism of population dynamics in a fishery [41,42]. The mechanism of density-dependent mortality is assumed to be predatory, and the assumption is now supported by experimental studies [43,44]. Furthermore, many recent studies have shown that density-dependent mechanisms are equally important for mortality and body growth in adults [45-47]. Density-dependent mortality has a great effect on estimating natural mortality, but it is difficult to estimate the value. We calculated the $R^{2}$ value according to density-dependent mortality and used the value with the greatest value of $R^{2}$.

In the above equation, the age index shows a jump occurring when the age stage moves from $i$ to $i+1$ at the time $t$, on 1 January. However, the last value at this year of the biomass for age $i$ is equal to the initial value at next year of the biomass for age $i+1$, but, despite the same time, the last value at this year of the biomass for age $i+1$ is the same as the initial value at next year of the biomass for age $i+1$. We added to the time $t$ of the initial value at next year of the biomass for age $i+1$ to distinguish between the left and the right at this time. Although Equation (1). represented reproduction as a fundamental-weighted sum of population, the effective fecundity was defined to increase the number of eggs for sandfish on the average total length. The formula for effective fecundity $f_{i}$ is well defined in Section 2.3.

\subsection{Age-Structured Biomass Model}

The main difference between the population model and the biomass model is the application of the growth rate. The reason why growth rates were considered is because of statistical studies showing 
that the number of eggs increases as weight increases. The growth equation used to convert from a population model to a biomass model is the von Bertalanffy model. The growth equation was applied to express both length and weight after assuming that the weight is proportional to the third power of the total length, i.e.,

$$
\begin{gathered}
L(t)=L_{\infty}\left\{1-e^{-K\left(t-t_{0}\right)}\right\} \\
W(t)=a_{w} L(t)^{3}=W_{\infty}\left\{1-e^{-K\left(t-t_{0}\right)}\right\}^{3}
\end{gathered}
$$

where $L_{\infty}$ and $W_{\infty}$ are asymptotic length and weight at which growth is zero, $\mathrm{K}$ is a von Bertalanffy growth coefficient, and $t_{0}$ is the hypothetical age at which a fish would have had zero length.

In order to convert Equation (1) to a biomass dynamic model, we define biomass of sandfish at age $i$ (representing by $B_{i}$ ) as the product of the population number of individuals at age $i$ (representing by $N_{i}$ ) and the average weight of sandfish at age $i$ (representing by $W_{i}$ ) as follows:

$$
B_{i}(t)=W_{i}(t) N_{i}(t)
$$

Using the system (1) and the derivative of Equation (3), we can convert the age-structured population model from population model (Equation (1)) to the age-structured biomass model of sandfish as follows (see Appendix A for more details about the system (2.4)):

$$
\left\{\begin{array}{c}
\frac{d B_{i}(t)}{d t}=g_{i}(t) B_{i}(t)-\left(M_{i}+\frac{D}{W_{0}(t)} B_{i}(t)\right) B_{i}(t)-C_{i}(t), \quad t \neq n, \\
B_{0}\left(t^{+}\right)=\sum_{i=0}^{5} f_{i} \frac{W_{0}(0)}{W_{i}(t)} B_{i}(t) \\
B_{j+1}\left(t^{+}\right)=B_{j}(t) \\
B_{5}\left(t^{+}\right)=B_{4}(t)+B_{5}(t)
\end{array}\right\} \quad t=n,
$$

where $g_{i}(\mathrm{t})=3 \mathrm{~K}\left(e^{K\left(i+t-\left[t_{0}\right]-t_{0}\right)}-1\right)^{-1}$ represents a growth rate at time $t$ and $i=1, \ldots, 5 ; j=$

\begin{tabular}{|c|c|c|}
\hline Parameter & Description & Unit \\
\hline$a_{p}$ & A constant in logistic regression of maturity & \\
\hline$B_{i}(t)$ & The biomass of sandfish of age $i$ at time $t$ & ton \\
\hline$b_{p}$ & A constant in logistic regression of maturity & \\
\hline$C_{i}(t)$ & Catch of sandfish of age $i$ at time $t$ & ton \\
\hline$D$ & A constant in density-dependent natural mortality & \\
\hline$E_{i}$ & Fecundity of a female at age $i$ & \\
\hline$f_{i}$ & Number of hatching eggs by female of age $i$ & \\
\hline$F_{i}(t)$ & Instantaneous rate of fishing mortality of sandfish of age $i$ at time $t$ & $\mathrm{yr}^{-1}$ \\
\hline $\mathrm{K}$ & The von Bertalanffy growth coefficient & \\
\hline$L_{0}$ & Length of hatched egg of sandfish & $\mathrm{cm}$ \\
\hline$L_{i}$ & Average total length at age $i$ & $\mathrm{~cm}$ \\
\hline$L(t)$ & Total length at time $t$ & $\mathrm{~cm}$ \\
\hline$L_{\infty}$ & Asymptotic length at which growth is zero & $\mathrm{cm}$ \\
\hline$M_{i}$ & Instantaneous rate of natural mortality of sandfish of age $i$ at time $t$ & $\mathrm{yr}^{-1}$ \\
\hline$N_{i}(t)$ & The number of sandfish of age $i$ at time $t$ & \\
\hline$P_{i}$ & Proportion of a female sandfish at age $i$ to participate in spawning & \\
\hline$q$ & A constant for size-specific natural mortality & \\
\hline$R_{S}$ & Sex ratio & \\
\hline$S_{h}$ & Average hatching rate of eggs & \\
\hline$t_{0}$ & Hypothetical age at which a fish would have had zero length & \\
\hline$V_{i}$ & The ratio between natural mortality at age $i$ and natural mortality at age 0 of sandfish & \\
\hline$W_{i}(\mathrm{t})$ & The weight of individual sandfish of age $i$ at time $t$ & $\mathrm{~g}$ \\
\hline
\end{tabular}
$0,1, \ldots, 3$ and $n \geq 1(n \in \mathbb{N})$. $C_{i}$ represents catch biomass at age $i$. Parameter and variables of the age-structured biomass model are listed and defined in Table 1.

Table 1. Parameter and variables that are used in a stage-structured model for sandfish. 


\subsection{Fecundity and Growth Rate}

In the system (1), the impulsive part of $B_{0}$ represents the total biomass of eggs at age 0 . We consider the number of hatched eggs by a female at age $i\left(f_{i}\right)$ as follows [16]

$$
f_{i}=E_{i} P_{i} R_{S} S_{h}
$$

where $E_{i}$ is the number of oocytes contained in the ovary of a female at age $i, P_{i}$ is the proportion of a female sandfish at age $i$ to participate in spawning, $R_{S}$ is a sex ratio, and $S_{h}$ is an average hatching rate of eggs. The average number of oocytes for each female at age $i\left(E_{i}\right)$ was estimated by regression analysis with body length (BL, cm) [3] as follows:

$$
F_{c}=0.4693 B L^{2.6825}
$$

where $F_{c}$ is fecundity of the sandfish. However, since we only have data for total length, the equation for length will be expressed in total length. Using the relationship between body length and total length $(\mathrm{TL}, \mathrm{cm})$ in Lee et al. [3], we convert the body length to the total length for Equation (6) as follows:

$$
\begin{gathered}
T L=1.1455 B L+0.0069 \\
F_{c}=0.4693\left(\frac{T L-0.0069}{1.1455}\right)^{2.6825} \\
F_{c}=0.3260(T L-0.0069)^{2.6825}
\end{gathered}
$$

Thus, we represent $E_{i}$ with respect to total length as follows:

$$
E_{i}=0.3260\left(L_{i}-0.0069\right)^{2.6825}
$$

where $L_{i}$ is total length at age $i$. We assume $L_{i}=L(\mathrm{i}+0.5)$, because we thought that the representative age for each age class is the median age of the age class. The proportion of a female sandfish at age $i$ to participate in spawning $\left(P_{i}\right)$ was estimated by logistic regression with total length using 126 female samples collected during spawning season (December 2005 and December 2006) as follows:

$$
P_{i}=\frac{1}{1+e^{-a_{p}-b_{p} L_{i}}}
$$

where $a_{p}$ and $b_{p}$ are the constants in logistic regression of $P_{i}$. Although the estimated value of $P_{0}$ and $P_{1}$ are positive, we assumed $P_{0}=P_{1}=0$, because sandfish is known to start spawning in 2 years $[3,4]$. Logistic regression tool in Matlab was used to estimate parameters in Equation (7).

A nonlinear least squares regression was used to fit Equation (7) based on annulus counting of otoliths extracted from 46 female sandfish collected in the eastern coastal waters of Korea, from 2005 to 2008. Although the growth rate is sexually different, we assumed that growth equations of females and males are the same for simplicity. We assumed that the length at the time of hatching, $L_{0}=1.3 \mathrm{~cm}$ [48]. Thus, $t_{0}$ can be derived as follows: $t_{0}=K \ln \left(1-\frac{L_{0}}{L_{\infty}}\right)$. Finally, we assumed that the sex ratio rate $R_{s}$ and average hatching rate $S_{h}$ are, respectively, $\frac{2}{3}$ [1] and $0.27 \%$ [49].

\subsection{Age-Dependent Natural Mortality}

As accepting the bigger-is-better hypothesis [16,50,51], we take the size-dependent natural mortality as follows:

$$
M(t)=\frac{L_{\infty} M_{\infty}}{L(t)^{\gamma}}=\frac{q}{\left\{L_{\infty}\left(1-e^{-K\left(t-t_{0}\right)}\right)\right\}^{\gamma}}
$$


where $M(t)$ is natural mortality at time $t, L_{\infty}$ and $W_{\infty}$ are asymptotic length and weight at which the growth rate becomes zero, $q$ and $\gamma$ are the constants for size-dependent natural mortality.

Here, we used the constants for size-dependent natural mortality $\gamma$ as 1, because Equation (8) is integrable at time $t$ when $\gamma=1$. The constant $\gamma$ is known to have an important relationship with natural mortality $[17,18]$. To evaluate influences of the assumed value of $\gamma$ for the natural mortality, we conducted sensitivity analyses for natural mortality at age 0 and age-specific natural mortality rate by varying $\gamma$ from 0.85 to 1.15 in Section 3.3. In this subsection, however, we simply followed the past studies that proposed that the natural mortality rate is inversely proportional to the size of animals at the species level $[16,21,22,52]$ so that it is simply because Equation (8) with $\gamma=1$ is integrable at time $t$.

Thus, natural mortality $M_{i}$ at age $I$ is defined by the cumulative natural mortality during the period of age $i$. Using Equation (8), the mortality $M_{i}$ is calculated as follows:

$$
M_{i}=\int_{i}^{i+1} M(t) d t=\int_{i}^{i+1} \frac{q}{L_{\infty}\left\{1-e^{-k\left(t-t_{0}\right)}\right\}} d t=\frac{q}{K L_{\infty}} \ln \left(\frac{e^{K\left(i+1-t_{0}\right)}-1}{e^{K\left(i-t_{0}\right)}-1}\right)
$$

Therefore, we can represent natural mortality by the size-specific mortality, $q$, for each age class. Here, we can define natural mortality of all ages as follows:

$$
\begin{gathered}
M_{0}=\frac{q}{K L_{\infty}} \ln \left(\frac{e^{K\left(1-t_{0}\right)}-1}{e^{-K t_{0}}-1}\right) \\
M_{i}=V_{i} M_{0} \\
V_{i}=\frac{\ln \left\{\left(e^{K\left(i+1-t_{0}\right)}-1\right) /\left(e^{K\left(i-t_{0}\right)}-1\right)\right\}}{\ln \left\{\left(e^{K\left(1-t_{0}\right)}-1\right) /\left(e^{-K t_{0}}-1\right)\right\}}
\end{gathered}
$$

Because the parameters in $V_{i}$ can be estimated by regression analysis on the von Bertalanffy growth equation, age-specific natural mortality rate can be expressed as a scalar multiplication of natural mortality at age 0 . Thus, we are able to estimate natural mortality of all ages by estimating $q$.

\subsection{Method of Estimating Natural Mortality}

To estimate $q$, we consider a derivative of total catch of the n-th year in system (4) as follows:

$$
\frac{d C(t)}{d t}=\frac{d}{d t} \sum_{i=1}^{5} C_{i}(t)=\sum_{i=1}^{5} F_{i}(t) B_{i}(t), n-1 \leq t<n(n \in \mathrm{N})
$$

There exists fishing mortality of all ages $F_{\text {totlal }}(n)$ at the $n$-th year such that

$$
\sum_{i=1}^{5} F_{i}(t) B_{i}(t)=F_{\text {total }}(n) \sum_{i=1}^{5} B_{i}(t) .
$$

By combining and integrating Equations (10) and (11),

$$
C(n)=F_{\text {total }}(n) \sum_{i=1}^{5} \int_{n-1}^{n} B_{i}(t) d t,
$$

where $C(n)$ is the total catch of all ages at the $n$-th year. Because fishing mortality is expressed as a product of the fishing effort $F_{\text {effort }}(n)$ and catchability coefficient $\alpha$, we obtain the equation for CPUE and biomass as follows:

$$
\operatorname{CPUE}(n)=\frac{C(n)}{F_{\text {effort }}(n)}=\alpha \sum_{i=1}^{5} \int_{n-1}^{n} B_{i}(t) d t(n \in \mathrm{N}) .
$$

To calculate the right-hand side of Equation (12) for a given initial value, system (4) can be solved with respect to $q$. 
However, it is difficult to obtain the exact solution of system (4), and we numerically calculated the right-hand side of Equation (12). Thus, for a given initial value, we estimated $q$ by taking the one that showed the greatest value of coefficient of determination $R^{2}=1-\frac{S S_{r e s}}{S S_{t o t}}$ as a measure of goodness-of-fit based on annual CPUE data by using linear regression for Equation (12). This quantity is equivalent to minimize the least square error. Thus, we can estimate the natural mortality for each age according to the assumption of the initial value using Equation (9). Ratio of initial biomass $B(0)$ for each age affects the estimation result of natural mortality. Because it is difficult to consider all cases for the ratio of initial biomass, we assumed a reasonable ratio of initial biomass by combining the ratio of initial biomass for each age at long-term equilibrium in the absence of fishing and the ratio of catch for sandfish. Matlab was used for all simulation and glmfit and nlinfit packages in Matlab were used for regression analysis.

\section{Numerical Results}

\subsection{Fecundity and Growth Rate}

The derived logistic curve of size-dependent probability of an average female sandfish at age $i$ to matures and participate in spawning $\left(P_{i}\right)$ is shown in Figure $2 \mathrm{a}$ and the equation is as follows:

$$
P_{i}=\frac{1}{1+e^{17.7042-1.0446 L_{i}}} .
$$

The derived mean length at sexual maturity $\left(L_{50}\right)$ was $16.9 \mathrm{~cm}$ TL (age $\left.=1.72\right)$ for female sandfish. Note that in order to estimate the coefficients for Equation (7) by the nonlinear least squares regression, we used the annulus counting of otoliths extracted from 126 female sandfish collected in the eastern coastal waters of Korea, from 2005 to 2008, and obtained those values of the significant level less than 0.05 . The derived von Bertalanffy growth curves for female sandfish are shown in Figure $2 \mathrm{~b}$. The assumed total length at the time of hatching is $\mathrm{L}_{0}=1.3 \mathrm{~cm}$, and the derived equations in length and weight are as follows:

$$
\begin{gathered}
L(t)=25.7678\left(1-e^{-0.5920(t+0.0874)}\right), \\
W(t)=132.0908\left(1-e^{-0.5920(t+0.0874)}\right)^{3} .
\end{gathered}
$$
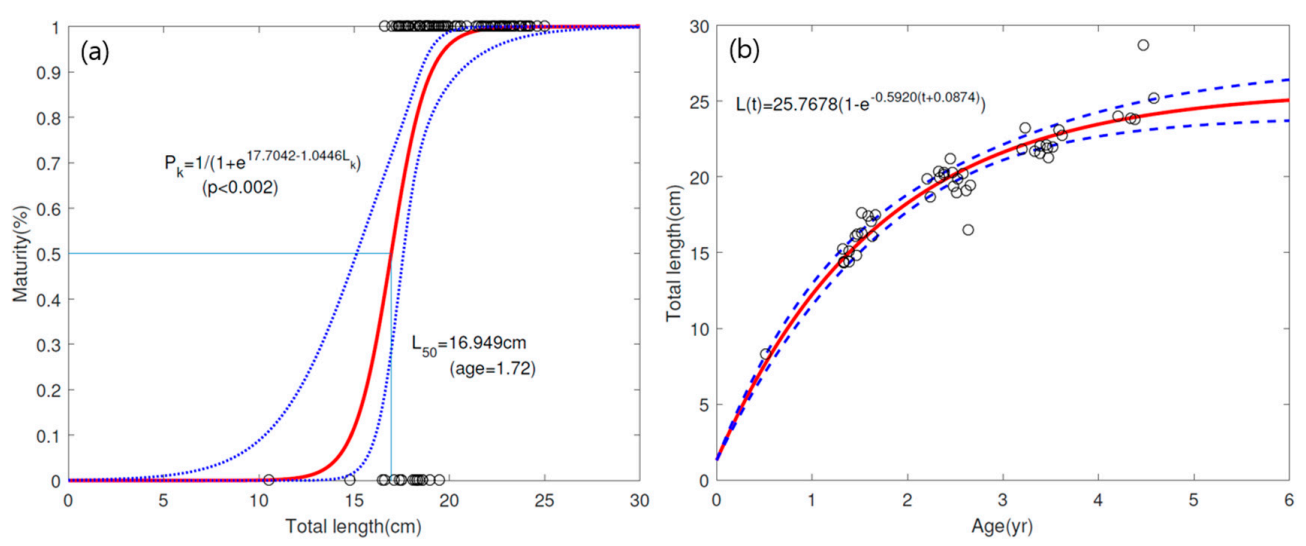

Figure 2. (a) Logistic regression curve for probability of participation for spawning with total length of 126 female sandfish (Arctoscopus japonicas) collected during spawning season (December 2005 and December 2006) in the eastern coastal waters of Korea; (b) Nonlinear regression curve of von Bertalanffy growth equation based on annulus counting of otoliths extracted from 46 female sandfish collected from 2005 to 2008, in the eastern coastal waters of Korea. The two dotted lines represent the $95 \%$ confidence interval for regression. 


\subsection{Natural Mortality and Initial Total Biomass}

In order to assume initial value, we calculate reasonable ratio of initial biomass based on age 6 by the fecundity and catch data for sandfish in 1994 as follows:

$$
B(0)=(0.4 x, 9.23 x, 5.25 x, 2.88 x, 1.66 x, x), x \in \mathrm{R}
$$

where $x$ is the sum of the initial biomass $\left(\sum B_{i}(0)\right)$ of all ages. As $\sum B_{i}(0)$ in 1994, the value of $R^{2}$ for regression of CPUE and total biomass is calculated for each $\mathrm{q}$ and $x$ (Figure 3a); $\mathrm{q}$ does exist for $\sum B_{i}(0)>4725$, and $R^{2}>0$ gradually decreases with increasing $\sum B_{i}(0)$ when $\sum B_{i}(0)>8925$. The estimated $M_{0}$ by Equation (9) that showed the greatest value of $R^{2}$ for each total biomass was derived, as shown in Figure $3 b$.
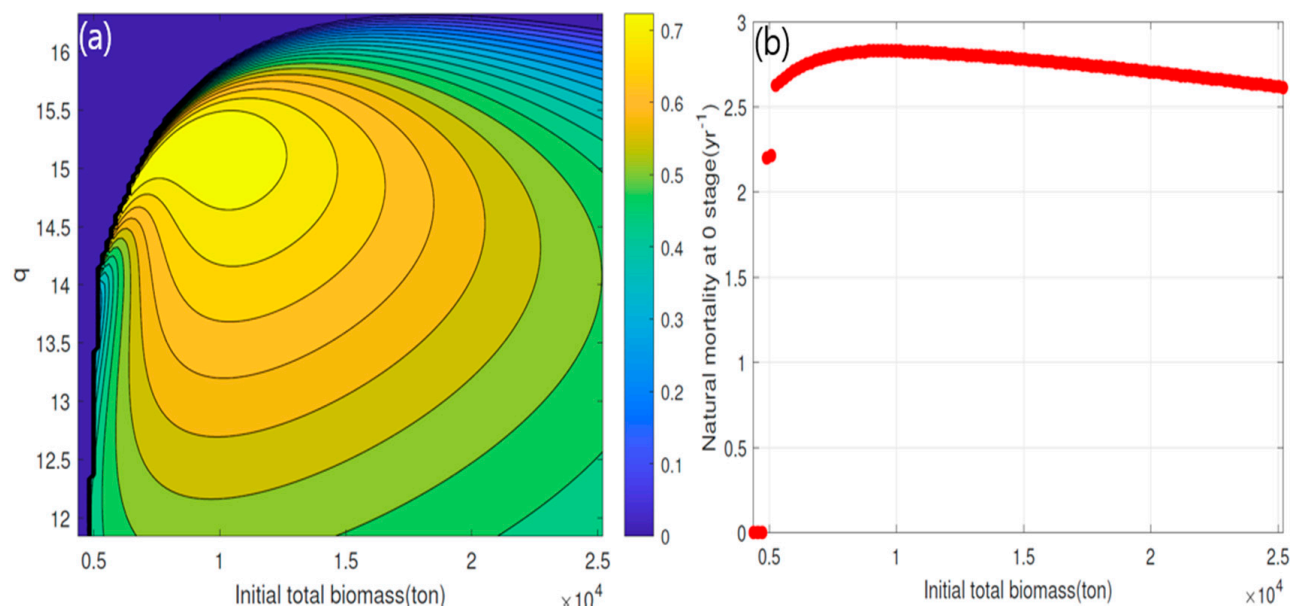

Figure 3. (a) Distribution of $R^{2}$ for initial total biomass and q; (b) $M_{0}$ corresponding to maximum $R^{2}$ for each initial total biomass.

Although all $M_{0}$ corresponding to the greatest value of $R^{2}$ for each total biomass were valuable statistically, in particular, the values of $M_{0}$ and $\sum B_{i}(0)$ having the greatest value of $R^{2}$ among them were $2.83 \mathrm{yr}^{-1}$ and 8925 ton, and then natural mortality from age 1 to 5 were $0.9925,0.7591,0.6733,0.6339$, and $0.6141 \mathrm{yr}^{-1}$, averaged $0.7346 \mathrm{yr}^{-1}$. The cumulative instantaneous mortality rate from age 1 to 5 was $3.6728 \mathrm{yr}^{-1}$, which means, among 10,000 individuals at age $1 \mathrm{yr}$ (12.23 cm TL), only 254 individuals survive to age 6 yr $(25.07 \mathrm{~cm}$ TL). We assumed that the density-dependent mortality coefficient D as $1.95 \times 10^{-6}$ because it has the greatest value of $R^{2}$ for various $D$, as shown in Figure 4 .

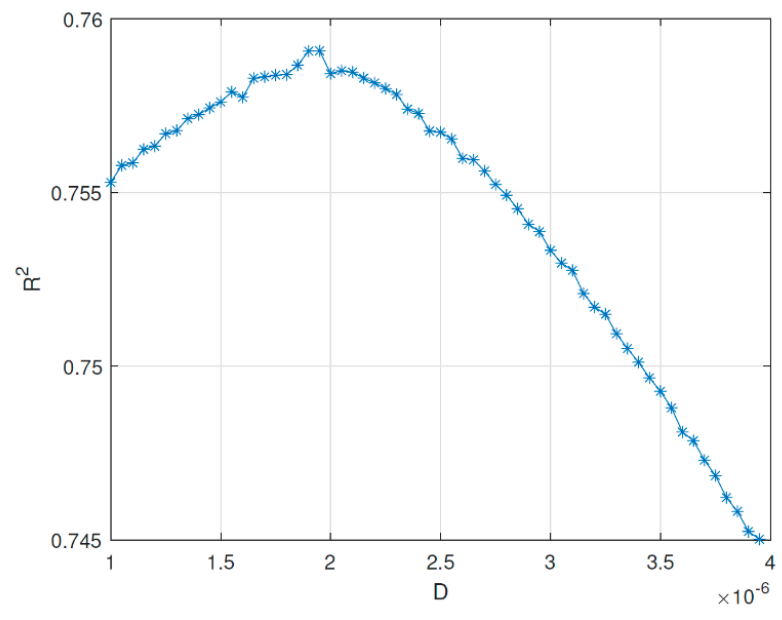

Figure 4. The greatest value of $R^{2}$ for the density-dependent mortality coefficient $D$. 
In order to verify that the age-specific natural mortality is properly estimated, it is necessary to compare observed length frequencies of sandfish with the estimated length frequency in the model. Using total length of 172 female sandfish collected in the eastern coastal waters of Korea from 2005 to 2008, the results of the Kolmogorov-Smirnov test showed that the distributions of observed and estimated length frequencies (\%) of sandfish in the east coastal waters of Korea did not differ significantly (Figure 5).

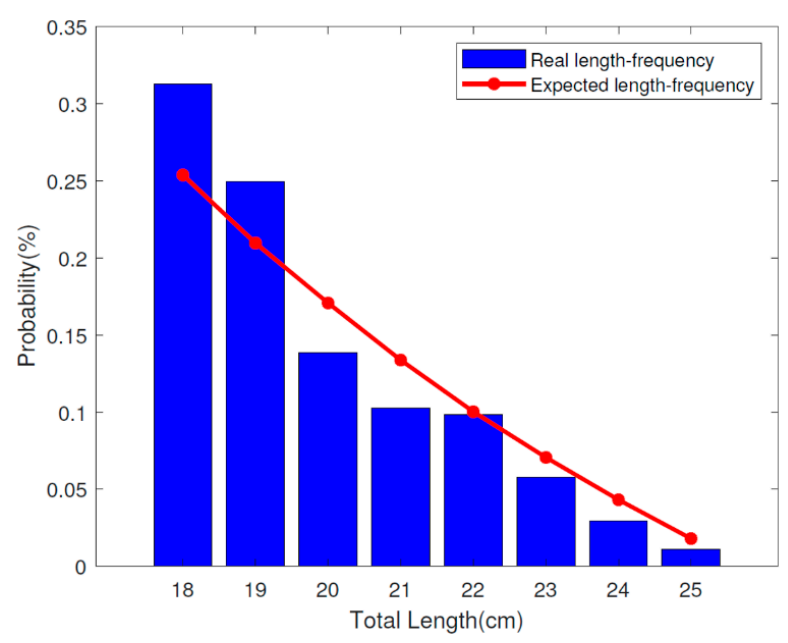

Figure 5. Modeled (redline) and observed (blue bar) length frequencies of sandfish in the eastern coastal waters of Korea from 2005 to 2008 when $\sum B_{i}(0)=8925$ and $M_{0}=2.83$.

\subsection{Sensitivity Analysis}

Figure 6 shows the age-specific natural mortality rate which is estimated when $\gamma$ is 0.85 to 1.15 under the initial total biomass in 1994. The values of largest $R^{2}$ corresponding to the various $\gamma$ are distributed from 0.7675 to 0.7593 and the sum of natural mortality of ages 0 to $5\left(\sum M_{k}\right)$ ranged from 6.6637 to 6.3420 (Figure 6a). The difference of $R^{2}$ and $\sum M_{k}$ are not sensitive at $1.08 \%$ and $4.83 \%$, respectively. The derived values of $M_{0}$ increased by approximately $23.27 \%$ from 2.5381 to 3.1286 when $\gamma$ increased from 0.85 to 1.15 , but natural mortality from age 1 to 5 decreased by 15.06, 21.76, 24.54, 25.90 , and $26.60 \%$ (Figure $6 \mathrm{~b}$ ). This indicates that if the value of $\gamma$ increases, the difference of the natural mortality of adult increases and the natural mortality of juvenile has a greater effect on the biomass than the natural mortality of adult fish.
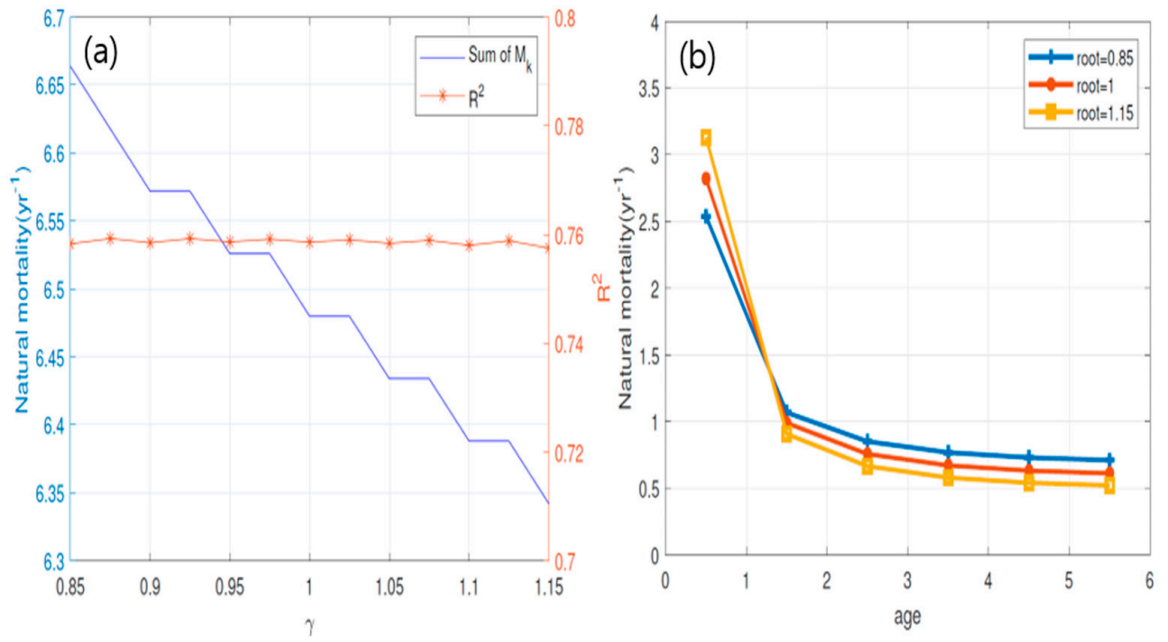

Figure 6. (a) Variation of $\sum M_{k}$ and $R^{2}$ when $\gamma$ is 0.85 to 1.15 ; (b) Estimated natural mortality of sandfish at all ages for each $\gamma=0.85,1$, and 1.15 . 
We compared the estimated values of natural mortality in our study to other papers for the purpose of examining the difference between the results of natural mortality of other papers, as shown in Table 2. The results show that the average natural mortality of sandfish derived from our method was 5.24 and 1.52 times higher than those derived from the methods by Pauly [13], and Zhang and Megrey [14], respectively. We do not consider that the methods of Pauly [13] or Zhang and Megrey [14] are more appropriate in estimating natural mortality of sandfish than our method, because their estimates of natural mortality were based on only growth and water temperature, but we additionally considered reproduction and catch. The natural mortality by Pauly method tends to be relatively low as compared with those estimated by the other methods $[16,53]$.

Table 2. Comparison of the estimates of natural mortality of sandfish based on their fecundity, growth rate, and catch data using the various methods.

\begin{tabular}{cccc}
\hline Methods & Model & M (Average) & Reference \\
\hline Pauly (1980) & $\log _{10} M=$ & $\begin{array}{l}-0.0066+0.6543 \log _{10} K \\
-0.279 \log _{10} L_{\infty} \\
+0.4634 \log _{10} W T\end{array}$ & 0.14 \\
\hline $\begin{array}{c}\text { Zhang and Megrey } \\
(2006)\end{array}$ & $M=\frac{-b \pm \sqrt{b^{2}-4 a c}}{e^{K\left(0.44 * t_{\max }-t_{0}\right)}-1}$ & 0.482 & {$[14]$} \\
\hline $\begin{array}{c}\text { Peterson and } \\
\text { Wroblewski (1984) }\end{array}$ & $M_{W}=1.92 W^{-0.25}$ & $0.5824-0.8212$ & \\
\hline Lorenzen (1996, 2000) & $M_{W}=3 W^{-0.288}$ & $0.7591-1.1278$ \\
\hline This work & $M_{i}=\frac{q}{K L_{\infty}} \ln \left(\frac{e^{K\left(i+1-t_{0}\right)}-1}{e^{K\left(i-t_{0}\right)}-1}\right)$ & $0.6141-0.9925$ & \\
\hline
\end{tabular}

In addition, range of estimated natural mortality of sandfish by the methods of Lorenzen [20] and Peterson and Wroblewski [18] defined the relationship between body weight and natural mortality of various fish species and showed a similar range of natural mortality of sandfish estimated by our method. To compare with our results, we changed the form of their results depending on the value of $\gamma$ as follows:

$$
\begin{gathered}
M_{W}=2.8987 W^{-0.325}, \text { if } \gamma=0.975, \\
M_{W}=3.0004 W^{-0.333}, \text { if } \gamma=1, \\
M_{W}=3.1214 W^{-0.342}, \text { if } \gamma=1.025 .
\end{gathered}
$$

The instantaneous rates of natural mortality by our method, when $0.925 \leq \gamma \leq 1.025$, were within the $90 \%$ confidence interval of Lorenzen's result for weight exponent $([-0.351,-0.257])$ and coefficient ([2.84, 4.49]) [20]. This result shows that our method of estimated natural mortality of sandfish is a reasonable method.

\subsection{Estimated Fishing Mortality and Total Biomass}

Fishing mortality rates can also be estimated through the estimated natural mortality and biomass as follows:

$$
\frac{\frac{g_{i, j}-\left(M_{j}+F_{i, j}\right)}{D} B_{i, j}}{B_{i, j}-\left(B_{i, j}-\frac{g_{i, j}-\left(M_{j}+F_{i, j}\right)}{D}\right) \mathrm{e}^{g_{i, j}-\left(M_{j}+F_{i, j}\right)}}-B_{i+1, j}=0,
$$

where $F_{i, j}, g_{i, j}$, and $B_{i, j}$ are a fishing mortality, growth rate, and biomass at age $j$ after $i$ month from 1994. Since Equation (13) is an implicit type for $F_{i, j}$, we calculated fishing mortality using vpasolve in Matlab. Figure 7a,b shows, respectively, the monthly-averaged fishing mortality of sandfish from 1994 to 1998 and from 2005 to 2009 for $\sum B_{i}(0)=8925$ and $M_{0}=2.83$. The estimated annual-averaged fishing mortality from age 1 to 5 were $(0.0936,0.4596,0.3589,0.1466,0.0154)$ and $(0.0644,0.3381,0.2224,0.0585,0.0034)\left(\mathrm{yr}^{-1}\right)$, respectively. The main fishing period was from May to 
December before 2000, while the period changed from October to December after 2000. Furthermore, the averaged fishing mortality for all age classes from 1 to 5 yr were 0.1790 and 0.1145 , which means that approximately $16.39 \%$ and $10.82 \%$ of the total biomass were caught overall. These fishing mortalities correspond to $24.37 \%$ and $15.59 \%$ of the natural mortality.
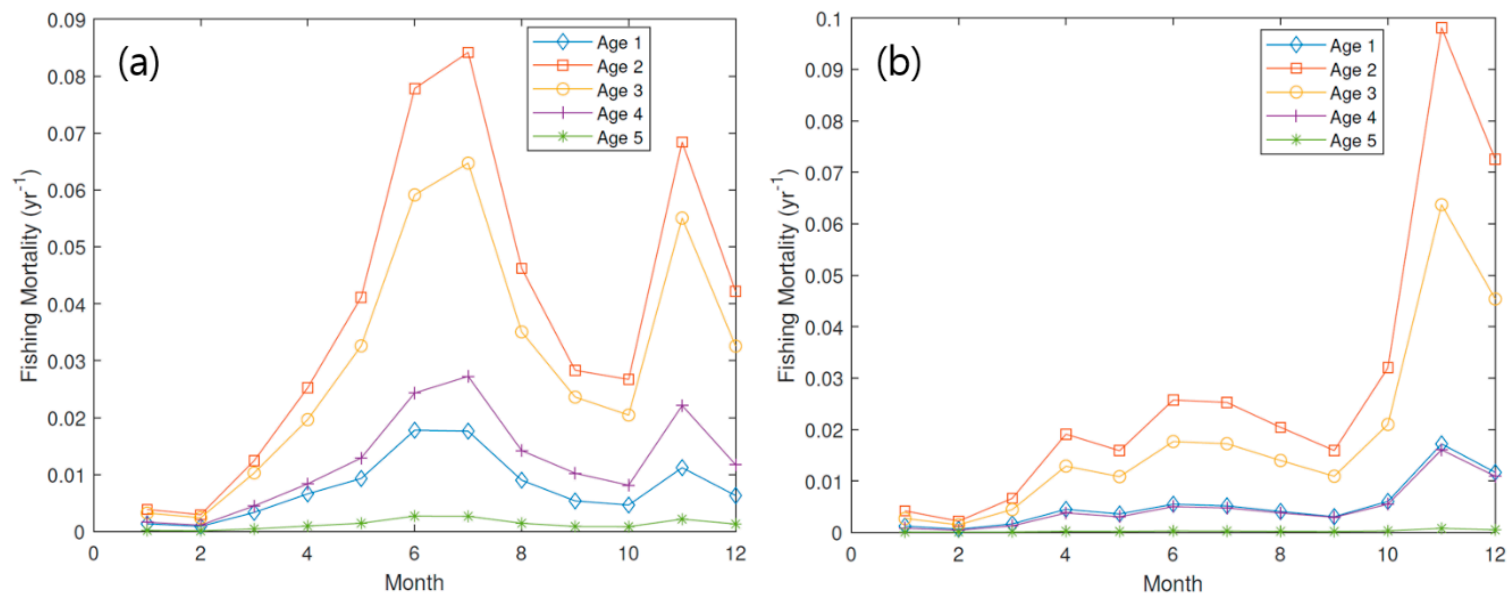

Figure 7. Monthly averaged fishing mortality of sandfish in the eastern coastal waters of Korea when $\sum B_{i}(0)=8925$ and $M_{0}=$ 2.83. (a) Between 1994 and 1998; (b) Between 2005 and 2009.

The annual total biomass of sandfish simulated from 1994 to 2009 when $\sum B_{i}(0)=8925$ tons and $M_{0}=2.83 \mathrm{yr}^{-1}$ is given in Figure 8a. The estimated annual total biomass for 1994 and 2010 were 8925 and 30,089 tons, the total biomass in 2010 was 3.37 times larger than 1994. As an initial value of the estimated biomass in 2010, Figure 9 shows rate of increase fishing intensity relative to the estimated fishing mortality in Figure 7b. Fishing intensity increased on average by 85.5\% from 2010 to 2019 , especially by $230 \%$ in 2016 . As a result, total biomass in 2019 would decrease by $20.5 \%$ as compared with 2010 (Figure 8b).
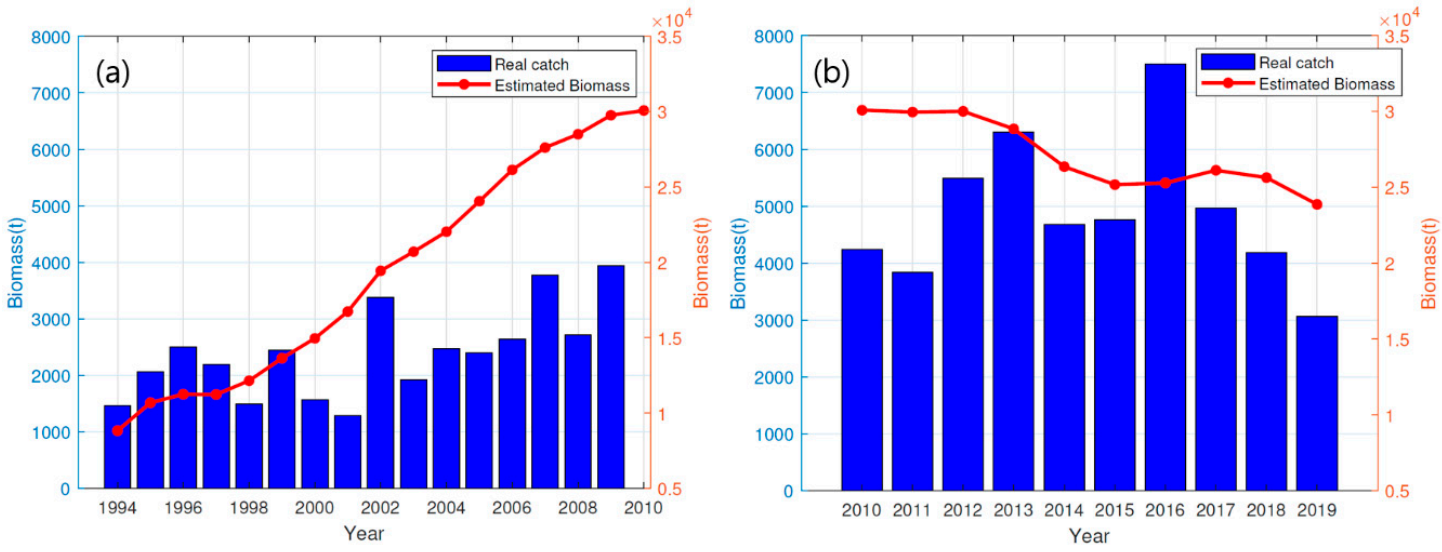

Figure 8. Estimated annual total biomass (redline) and the catch (blue bar) in the eastern coastal waters of Korea. (a) Between 1994 and 1998; (b) Between 2005 and 2009. 


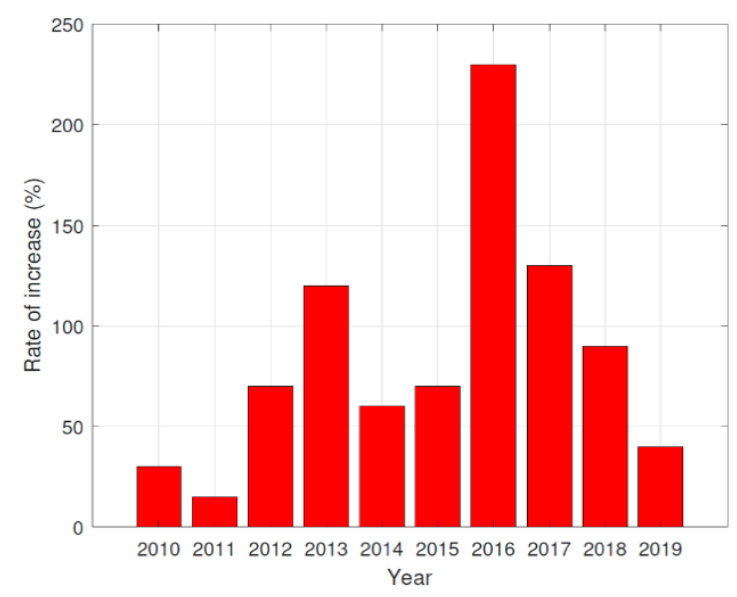

Figure 9. Rate of increase of fishing intensity relative to the estimated fishing mortality monthly averaged fishing mortality between 2005 to 2009.

\section{Discussion}

We proposed the age-structured biomass model of sandfish with an impulsive dynamical system. To estimate the natural mortality and fishing mortality of sandfish, we considered their catch and initial total biomass. Past studies did not consider fecundity, catch, and initial value simultaneously to their estimates of natural mortality $[16-18,25]$. Our approach can be extended to be applied for estimating natural and fishing mortality for other fish species of total spawner.

In order to estimate natural mortality of sandfish, we proposed the age-structured biomass model based on the effective fecundity and growth rate according to initial biomass, which is an advantage such that natural mortality can be obtained according to the level of the resource. To estimate fishing mortality, we defined the formula for the fishing mortality by using the estimated natural mortality and biomass depending on the initial total biomass. Since it is difficult to estimate natural mortality of larvae and juvenile, it can be estimated by applying the method of age-specific natural mortality. Although we assumed that $\gamma=1$ in Equation (8), the difference of $R^{2}$ and $\sum M_{k}$ are not sensitive. Our approach assumes that natural mortality depends on the initial biomass of fish in each year, and it can be useful to predict and manage fish biomass under various resource level scenarios. The higher estimates of natural mortality derived by our approach suggests that the density-dependent processes affecting the natural mortality need to be considered and should be included in the natural mortality. We expect that our approach and method can be extended to other fish species.

We assumed that the catchability coefficient $(\alpha)$ is a constant [54], but the catchability generally varies over time, which affects fish vulnerability to fishing gear, fishing strategy, and fish biology, including individual behaviors and responses to environmental factors [55]. We have estimated age-specific natural mortality according to the assumptions of initial total biomass, but it is not possible to compare what is the best one among estimated natural mortality rates. The range of realistic natural mortality can be determined through the ratio between the estimated natural mortality rate and the fishing mortality rate according to the initial total biomass. In addition, the relationship between total biomass and natural mortality can be formulated, in the future, using the results of this study. For more contribution to fisheries management for sandfish stock in Korea, we plan to conduct optimal harvest strategies according to resource level for resource recovery based on outcomes of this study.

Author Contributions: Conceptualization, S.K.; Data curation, D.K.; Formal analysis, S.J.; Investigation, G.C. and I.H.J.; Methodology, S.K.; Software, I.J.; Validation, S.J.; Visualization, I.H.J.; Writing-original draft, G.C.; Writing-review \& editing, G.C. and S.K. All authors have read and agreed to the published version of the manuscript.

Funding: This research was funded by the National Research Foundation of Korea (NRF) grant funded by the Ministry of Science and ICT of Korea government (NRF-2020R1C1C1A01012557; NRF-2017R1E1A1A03070224; NRF-2017R1A5A1015722). 
Conflicts of Interest: The authors declare no conflict of interest.

\section{Appendix A Constructing an Age-Structured Biomass Model}

In this appendix, we derive the age-structured biomass model from the age-structured population model. Biomass of sandfish $B_{i}$ at age $i$ is defined by the product of population and weight of sandfish $B_{i}(\mathrm{t})=W_{i}(t) N_{i}(t)$ at age $i$ and its time derivative as follows:

$$
\frac{d B_{i}(t)}{d t}=N_{i}(t) \frac{d W_{i}(t)}{d t}+W_{i}(t) \frac{d N_{i}(t)}{d t}
$$

In Equation (A1), the time derivative of $B_{i}(t)$ is represented by the increased biomass for growth and the decreased biomass for death. To express the right-hand side of Equation (A1) for $B_{i}$, the time derivative of $W_{i}(t)$ is calculated from Equation (2) as follows:

$$
\frac{d W_{i}(t)}{d t}=3 K W_{i}(t)\left(e^{K\left(i+t-[t]-t_{0}\right)}-1\right)^{-1}
$$

where the square bracket $[\cdot]$ denotes the Gauss' notation. Here, we can define the growth rate $\left(g_{i}(t)\right)$ at age $i$ as following:

$$
g_{i}(t)=\frac{1}{W_{i}(t)} \frac{d W_{i}(t)}{d t}
$$

Because system (1) is divided into two parts for time $t$, we derive system (4) by using Equation (A2) in conjunction with system (1) as following:

$$
\begin{aligned}
\frac{d B_{i}(t)}{d t}= & N_{i}(t) \frac{d W_{i}(t)}{d t}+W_{i}(t) \frac{d N_{i}(t)}{d t} \\
= & 3 K N_{i}(t) W_{i}(t)\left(e^{K\left(i+t-[t]-t_{0}\right)}-1\right)^{-1} \\
- & {\left[\left(M_{i}+D \frac{W_{i}(t)}{W_{i}(t)} N_{i}(t)\right) N_{i}(t)-H_{i}(t)\right] W_{i}(t) } \\
= & 3 K\left(e^{K\left(i+t-[t]-t_{0}\right)}-1\right)^{-1} B_{i}(t)-\left(M_{i}+\frac{D}{W_{i}(t)} B_{i}(t)\right) B_{i}(t)-C_{i}(t), \\
= & g_{i}(t) B_{i}(t)-\left(M_{i}+\frac{D}{W_{i}(t)} B_{i}(t)\right) B_{i}(t)-C_{i}(t), t \neq n \\
B_{0}\left(t^{+}\right)= & W_{0}(0) N_{0}\left(t^{+}\right)=W_{0}(t) \sum_{i=0}^{5} f_{i} N_{i}(t)=\sum_{i=0}^{5} f_{i} W_{0}(0) \frac{B_{i}(t)}{W_{i}(t)}, t=n \\
& B_{j+1}\left(t^{+}\right)=W_{j+1}\left(t^{+}\right) N_{j+1}\left(t^{+}\right)=W_{j}(t) N_{j}(t)=B_{j}(t), \\
& B_{5}\left(t^{+}\right)=W_{4}(t) N_{4}(t)+W_{5}(t) N_{5}(t)=B_{4}(t)+B_{5}(t),
\end{aligned}
$$

where $i=1, \ldots, 5$ and $j=0,1, \ldots, 3 ; \mathrm{n} \geq 1(n \in \mathbb{N})$. Hence, we obtain an age-structured biomass system (4).

\section{References}

1. Choi, S.H.; Chun, Y.Y.; Son, S.J.; Suh, H.K. Age, growth and maturity of sandfish, Arctoscopus japonicus (Steindachner) in the eastern sea of Korea. Bull. Natl. Fish. Res. Dev. Agency 1983, 31, 7-19.

2. Chyung, M.K. The Fishes of Korea; Il-Ji Sa Publishing Co.: Seoul, Korea, 1977; pp. 1-727.

3. Lee, H.W.; Kim, J.H.; Kang, Y.J. Sexual Maturation and Spawning in the Sandfish Arctoscopus japonicus in the East Sea of Korea. J. Korean Fish. Soc. 2006, 39, 349-356.

4. Mio, S. Studies on the population biology of the sandfish Arctoscopus japonicus (STEINDACHNER) I. Age, growth and maturity. Bull. Jpn. Sea Reg. Fish. Res. Lab. 1967, 18, 23-37. 
5. Nakabo, T. Fishes of Japan with Pictorial Keys to the Species; English Edition II; Tokai University Press: Tokyo, Japan, 2002.

6. Otsuai, A.; Tanaka, M. Ichthyology; Koseisha-Koseikaku Press: Tokyo, Japan, 1986; p. 1140.

7. Watanabe, K. A Study on Dynamics and Management of Sandfish Stocks Arctoscopus Japonicus in the Waters around Japan. Ph.D. Thesis, Tokyo University of Fisheries, Tokyo, Japan, 2004.

8. Myoung, J.G.; Kim, J.M.; Kim, Y.U. Egg development and morphology of sandfish, Arctoscopus japonicus larvae and juveniles reared in the laboratory. J. Korean Fish. Soc. 1989, 22, 129-137.

9. Okiyama, M. Studies on the population biology of the sand fish, Arctoscopus japonicus (Steindachner). II. Population analysis (preliminary report). Bull. Jpn. Sea Reg. Fish. Res. Lab. 1970, 22, 59-69.

10. Yanagimoto, K.; Ochi, H.; Lee, K.G.; Shibamoto, T. Antioxidative activities of fractions obtained from brewed coffee. J. Agric. Food Chem. 2004, 52, 592-596. [CrossRef]

11. Lee, S.I.; Yang, J.H.; Yoon, S.C.; Chun, Y.Y.; Kim, J.B.; Cha, H.K.; Choi, Y.M. Biomass estimation of sailfin sandfish, Arctoscopus japonicus, in Korean waters. Korean J. Fish. Aquat. Sci. 2009, 42, 487-493.

12. Watanabe, K.; Sugiyama, H.; Sugishita, S.; Suzuki, N.; Sakuramoto, K. Estimating and monitoring the stock size of sandfish Arctoscopus japonicus in the northern Sea of Japan. Fish. Sci. 2005, 71, 776-783. [CrossRef]

13. Pauly, D. On the interrelationships between natural mortality, growth parameters, and mean environmental temperature in 175 fish stocks. ICES J. Mar. Sci. 1980, 39, 175-192. [CrossRef]

14. Zhang, C.I.; Megrey, B.A. A revised Alverson and Carney model for estimating the instantaneous rate of natural mortality. Trans. Am. Fish. Soc. 2006, 135, 620-633. [CrossRef]

15. Quinn, T.J.; Deriso, R.B. Quantitative Fish Dynamics; Oxford University Press: Oxford, UK, 1999.

16. Jung, S.; Choi, I.; Jin, H.; Lee, D.; Cha, H.; Kim, Y.; Lee, J. Size-dependent mortality formulation for isochronal fish species based on their fecundity: An example of Pacific cod (Gadus macrocephalus) in the eastern coastal areas of Korea. Fish. Res. 2009, 97, 77-85. [CrossRef]

17. McGurk, M.D. Natural mortality of marine pelagic fish eggs and larvae: Role of spatial patchiness. Mar. Ecol. Prog. Ser. 1986, 34, 227-242. [CrossRef]

18. Peterson, I.; Wroblewski, J.S. Mortality rate of fishes in the pelagic ecosystem. Can. J. Fish. Aquat. Sci. 1984, 41, 1117-1120. [CrossRef]

19. Gulland, J.A. Natural mortality and size. Mar. Ecol. Prog. Ser. Oldendorf 1987, 39, 197-199. [CrossRef]

20. Lorenzen, K. The relationship between body weight and natural mortality in juvenile and adult fish: A comparison of natural ecosystems and aquaculture. J. Fish Biol. 1996, 49, 627-647. [CrossRef]

21. Beyer, J.E. Recruitment stability and survival: Simple size specific theory with examples from the early life dynamics of marine fish. Dana 1989, 7, 45-147.

22. Lorenzen, K. Allometry of natural mortality as a basis for assessing optimal release size in fish-stocking programmes. Can. J. Fish. Aquac. 2000, 57, 2374-2381. [CrossRef]

23. Hixon, M.A. Population dynamics of coral-reef fishes: Controversial concepts and hypotheses. Aust. J. Ecol. 1998, 23, 192-201. [CrossRef]

24. Powers, J.E. Age-specific natural mortality rates in stock assessments: Size-based vs. density-dependent. ICES J. Mar. Sci. 2014, 71, 1629-1637. [CrossRef]

25. Beverton, R.J.H.; Holt, S.J. On the Dynamics of Exploited Fish Populations; Chapman and Hall: London, UK, 1957.

26. Forrest, R.E.; McAllister, M.K.; Martell, S.J.; Walters, C.J. Modelling the effects of density-dependent mortality in juvenile Red Snapper caught as bycatch in Gulf of Mexico shrimp fisheries: Implications for management. Fish. Res. 2013, 146, 102-120. [CrossRef]

27. Ricker, W.E. Stock and recruitment. J. Fish. Board Can. 1954, 11, 559-623. [CrossRef]

28. Schaefer, M.B. Some aspects of the dynamics of populations important to the management of the commercial marine fisheries. Inter-Am. Trop. Tuna Comm. Bull. 1954, 1, $23-56$.

29. Gulland, J.A. Estimation of Mortality Rates, Annex to Arctic Fisheries Working Group Report; C.M. 1965/3; International Council for the Exploration of the Sea: Copenhagen, Denmark, 1965.

30. Jones, R. The Use of Length Composition Data in Fish Stock Assessments (with Notes on VPA and Cohort Analysis); FAO: Rome, Italy, 1981.

31. Pope, J.G. An investigation of the accuracy of virtual population analysis using cohort analysis. ICNAF Res. Bull. $1972,9,65-74$. 
32. Zhang, C.I.; Megrey, B.A. A Simple Biomass-Based Length-Cohort Analysis for Estimating Biomass and Fishing Mortality. Trans. Am. Fish. Soc. 2010, 139, 911-924. [CrossRef]

33. Ding, W. Optimal control on hybrid ODE systems with application to a tick disease model. Math. Biosci. Eng. 2007, 4, 633.

34. Aagard-Hansen, H.; Yeo, G.F. A stochastic discrete generation birth, continuous death population growth model and its approximate solution. J. Math. Biol. 1984, 20, 69-90. [CrossRef]

35. Nedorezov, L.V. Monofactor Theory of the Dynamics of Biological Populations; Institute of Biophysics SB AS USSR: Krasnoyarsk, Russia, 1989.

36. Nedorezov, L.V. Chaos and Order in Population Dynamics: Modeling, Analysis, Forecast; LAP Lambert Academic Publishing: Saarbrucken, Germany, 2012.

37. Mailleret, L.; Lemesle, V. A note on semi-discrete modelling in the life sciences. Philos. Trans. R. Soc. A 2009, 367, 4779-4799. [CrossRef]

38. Il'ichev, V.G. Evolution-stable parameters in a periodically changing environment. Autom. Remote Control 2004, 65, 612-624. [CrossRef]

39. Samoilenko, A.M.; Perestyuk, N.A. Impulsive Differential Equations; World Scientific: Singapore, 1995.

40. Shen, J.; Li, J.; Wang, Q. Boundedness and periodicity in impulsive ordinary and functional differential equations. Nonlinear Anal. 2006, 65, 1986-2002. [CrossRef]

41. Myers, R.A.; Cadigan, N.G. Density-dependent juvenile mortality in marine demersal fish. Can. J. Fish. Aquat. Sci. 1993, 50, 1576-1590. [CrossRef]

42. Rose, K.A.; Cowan Jr, J.H.; Winemiller, K.O.; Myers, R.A.; Hilborn, R. Compensatory density dependence in fish populations: Importance, controversy, understanding and prognosis. Fish Fish. 2001, 2, $293-327$. [CrossRef]

43. Forrester, G.E. Strong density-dependent survival and recruitment regulate the abundance of a coral reef fish. Oecologia 1995, 103, 275-282. [CrossRef] [PubMed]

44. Hixon, M.A.; Carr, M.H. Synergistic predation, density dependence, and population regulation in marine fish. Science 1997, 277, 946-949. [CrossRef]

45. Bevacqua, D.; Melia, P.; De Leo, G.A.; Gatto, M. Intra-specific scaling of natural mortality in fish: The paradigmatic case of the European eel. Oecologia 2011, 165, 333-339. [CrossRef]

46. Lorenzen, K.; Enberg, K. Density-dependent growth as a key mechanism in the regulation of fish populations: Evidence from among-population comparisons. Proc. R. Soc. Lond. Ser. B 2002, 269, 49-54. [CrossRef]

47. Sibly, R.M.; Hone, J. Population growth rate and its determinants: An overview. Philos. Trans. R. Soc. Lond. Ser. B 2002, 357, 1153-1170. [CrossRef]

48. Okiyama, M. Contrast in Reproductive Style between Two Species of Sandfishes (Family Trichodontidae). Fish. Bull. 1990, 88, 543-549.

49. Morioka, T.; Hotta, K. Spawning of Japanese sandfish Arctoscopus japonicus brood stock reared in pumped deep seawater and control of hatching. Deep Ocean Water Res. 2005, 6, 19-29.

50. Meekan, M.G.; Vigliola, L.; Hansen, A.; Doherty, P.J.; Halford, A.; Carleton, J.H. Bigger is better: Size-selective mortality throughout the life history of a fast-growing clupeid, Spratelloides gracilis. Mar. Ecol. Prog. Ser. 2006, 317, 237-244. [CrossRef]

51. Miller, T.J.; Crowder, L.B.; Rice, J.A.; Marschall, E.A. Larval size and recruitment mechanisms in fishes: Toward a conceptual framework. Can. J. Fish. Aquat. Sci. 1988, 45, 1657-1670. [CrossRef]

52. Beyer, J.E.; Kirchner, C.H.; Holtzhausen, J.A. A method to determine sizespecific natural mortality applied to west coast steenbras (Lithognathus aureti) in Namibia. Fish. Res. 1999, 41, 133-153. [CrossRef]

53. Garbin, T.; Castello, J.P.; Kinas, P.G. Age, growth, and mortality of the mullet Mugil liza in Brazil's southern and southeastern coastal regions. Fish. Res. 2014, 149, 61-68. [CrossRef]

54. Beverton, R.J.H.; Holt, S.J. A review of methods for estimating mortality rates in exploited fish populations, with special reference to sources of bias in catch sampling. Rapp P.-v. Reun CIEM 1956, 140, 67-83.

55. Arreguin-Sánchez, F. Catchability: A key parameter for fish stock assessment. Rev. Fish Biol. Fish. 1996, 6, 221-242. [CrossRef]

(C) 2020 by the authors. Licensee MDPI, Basel, Switzerland. This article is an open access article distributed under the terms and conditions of the Creative Commons Attribution (CC BY) license (http://creativecommons.org/licenses/by/4.0/). 